\title{
La prensa lucense ante el Estatuto de Autonomía de 1936
}

Recibido: 16 de noviembre de 2010

Aceptado: 29 marzo de 2011

Publicado: 31 de octubre de 2011
Paloma Abejón Mendoza

pabejonm@ccinf.ucm.es

Universidad Complutense de Madrid (España)

Resumen: Si hoy Galicia es considerada comunidad histórica junto a Cataluña y País Vasco es porque en 1936 se aprobó su primer Estatuto de Autonomía. Aquel primer texto fue presentado por Castelao y otros intelectuales y políticos al presidente de la República el 15 de julio de 1936, pero el estallido de la Guerra Civil, tres días después, hizo imposible su discusión y hubo que esperar 43 años, hasta 1979, para que en Galicia se hiciera realidad el sueño autonomista. El objeto de esta investigación es analizar cómo abordaron el fenómeno autonomista las publicaciones de la provincia de Lugo durante la Segunda República.

Palabras claves: Prensa, autonomía, Lugo, Segunda República.

Abstract: If Galicia is nowadays considered a historical community, along with Catalonia and Basque Country, is because Galicia approved, in referendum, its first Statute of Autonomy in 1936. That first Statutory text was presented by Castelao and other intellectuals and politicians to the President of Spain on July the 15th 1936. However the burst of Spanish Civil War, just three days later, prevented the discussions in Court and it was not until 43 years later (1979) when Galicia made its autonomist dream come true. The purpose of this research is to analyze how this autonomist phenomenon was approached by the existing publications in the province of Lugo during the Second Spanish Republic.

Key words: Press, Autonomy, Lugo, Second Spanish Republic. 


\section{Introducción y objetivos}

El Estatuto de Autonomía de Galicia de 1936 fue un proyecto redactado durante la Segunda República y aprobado en plebiscito el 28 de junio de 1936. Nunca llegó a entrar en vigor debido al estallido de la Guerra Civil (Galicia quedó en manos de los sublevados desde el inicio de la contienda) y aunque el 15 de julio de ese año Gómez Román y Castelao lo entregaron al entonces presidente de las Cortes españolas, Manuel Azaña, nunca cobró vigencia. Fue admitido a trámite en el Parlamento en febrero de 1938, pero eso fue todo lo lejos que pudo llegar. Hubo que esperar hasta noviembre de 1945 para que, simbólicamente en México, fuese aprobado, aunque, como era previsible, quedó en suspenso hasta el final de la dictadura.

Una de las cosas que más llama la atención de este primer Estatuto de Autonomía de Galicia es que salió adelante con un amplísimo respaldo ciudadano sin precedentes en dicha región. El 74.5\% del censo de aquella época aprobó en las urnas el proyecto autonomista y lo más sorprendente es que esa decisión ciudadana se dio sin que la prensa de aquella Segunda República hicieran una campaña masiva a favor del texto. Eso sí, sería injusto no recordar que las garantías de limpieza de los procesos electorales en la II República no eran las mismas que hoy en día y que han sido varios los grupos que han reconocido que hubo prácticas más que irregulares en aquel referéndum.

Esta investigación comenzó hace más de quince años con la intención de demostrar la aportación de los medios de comunicación gallegos de cara a la consecución del autonomismo. Para demostrarlo, nos planteamos un objetivo particular: analizar el tratamiento que dedicaron los periódicos y publicaciones de la provincia de Lugo al primer Estatuto de Autonomía de Galicia (1936).

A la vez, la investigación pretende demostrar si los gallegos (siempre condenados a ser en España "nacionalistas de segunda" debido a la fortaleza del nacionalismo vasco y catalán) tenían ya en la década del treinta su propia concepción sobre el autonomismo y el autogobierno.

El ámbito de la investigación se limita a la provincia de Lugo por la dificultad de encontrar ejemplares de todas y cada una de las múltiples publicaciones que circularon durante la II República, sobre todo por la falta de archivos de la época y porque muchas de ellas duraban escasamente semanas o meses. Se trata de una época convulsa y económicamente era difícil sostener proyectos editoriales serios, por lo que hubo un sinfín de intentos de publicaciones que no perduraron mucho en el tiempo.

Son muchas las preguntas que esta investigación ha pretendido resolver. ¿Cuántas publicaciones existían en la provincia de Lugo durante el quinquenio de la II República? ¿Cuántas se conservan aún hoy? ¿Puede la prensa permanecer ajena a los acontecimientos históricos o es necesariamente partícipe de ellos? ¿Intentan los políticos controlar los medios de comunicación en los momentos decisivos? ¿Es tanto el poder de la prensa como se dice? ¿Puede una campaña en los medios hacer cambiar el resultado de las urnas en unas elecciones? 
Se eligió analizar el fenómeno autonomista en relación a ese primer Estatuto de Autonomía de Galicia también como un intento de valorar dicho texto. Quizá es uno de los grandes desconocidos de la historia española y hoy, cuando se ha vuelto a reabrir la necesidad de reformar el actual texto del Estatuto de Autonomía de Galicia (que rige desde 1989), cobra mayor importancia aquel primer texto de 1936 como antecedente histórico.

Aquel primer Estatuto de Galicia fue un primer paso en favor de la Autonomía que duró muy poco debido a la irrupción violenta de la Guerra Civil, pero actualmente nos interesa no sólo a nivel político, sino también como pieza clave para analizar los mensajes periodísticos de contenido autonomista de aquella época para poder, así, compararlos con los que se están sucediendo en la actualidad.

La investigación permitirá también demostrar que el enfrentamiento ideológico de los medios de comunicación no es un fenómeno nuevo y que la crispación mediática es tan antigua como la política misma. Además, se pretende analizar el discurso político de la II República en relación al autonomismo. ¿Cómo era el discurso de los nacionalismos entre 1934 y 1936 ? ¿Y el de quienes defendían entonces la unión de España a ultranza en contra de las autonomías? ¿Ha variado el lenguaje político de entonces hasta hoy?

El dilema derecha-izquierda-nacionalismo y su forma de ver el fenómeno autonomista son el núcleo principal del estudio, del que buena parte se ha dedicado a investigar para intentar encontrar tanto en bibliotecas como en archivos privados ejemplares de todos y cada uno de los periódicos que se editaban en aquella época en la provincia de Lugo.

Conviene aclarar, no obstante, que el autonomismo no era un fenómeno tan en boga durante la II República como lo es hoy. No hubo en toda la provincia de Lugo ningún medio de comunicación que tuviera como objetivo principal la defensa del autogobierno de Galicia aunque sí hubo, sin embargo, medios claramente favorables a la autonomía y otros visceralmente opuestos. Basta comparar, por ejemplo, los postulados de La Comarca, de Ribadeo, con los de La Voz de la Verdad, órgano católico editado en la capital. De todos modos, lo más reseñable o lo más habitual en la mayoría de los medios de comunicación de esa época fue el principio de "nadar y guardar la ropa", y eso a pesar de la clara implicación partidista de los periódicos de la II República.

Se puede afirmar que, en la década del treinta, los partidos gallegos (y por extensión, los medios de comunicación) eran contrarios o reticentes o indiferentes a la autonomía gallega. Muy pocos apostaron claramente por ese Estatuto que, sin embargo, las urnas respaldaron masivamente.

El panorama era el siguiente: Las fuerzas políticas de derechas eran contrarias porque creían que acabaría con la unidad nacional. Sostenían, con un discurso muy similar al actual, que los anhelos autonomistas equivalían al separatismo; en el centro republicano había una parte hostil al Estatuto (el Partido Republicano Radical) pero también había otro republicanismo autonomista (la ORGA de Casares Quiroga); y, finalmente, dentro de la izquierda estaban el PSOE y los anarquistas, ambos hostiles al Estatuto. De hecho, el PSOE mantuvo una reunión en Monforte en octubre de 1931 en la que acordó oponerse a la autonomía. 
En resumen, exceptuando a los nacionalistas y a un reducido sector autonomista republicano, el resto del espectro político no era favorable a la aprobación del Estatuto gallego.

Esto se trasladó en el contexto de los medios de comunicación. Muy pocos periódicos de la provincia de Lugo apostaron claramente por defender la autonomía. Se puede afirmar que los periódicos respondían, más o menos fielmente (aunque con honrosas excepciones), a los principios ideológicos de los partidos de la época. Así pues, también fueron contrarios, reticentes o cuando menos indiferentes al proceso autonómico.

De todas formas, pese a esta mayoritaria indiferencia hacia el autonomismo y hacia aquel primer Estatuto de Autonomía de Galicia, una primera conclusión tras estos años de investigación es que la prensa no fue solamente transmisora de hechos y noticias, sino que los periódicos actuaron indudablemente como mediadores en los conflictos ideológicos y como transmisores de ideas, creencias, conocimientos y opiniones de la sociedad.

El periodo elegido (1931-1936) comprende cinco años que cambiaron el rumbo de la historia no sólo de Lugo, sino de Galicia y de toda España. Los periódicos no fueron testigos imparciales del transcurrir de los acontecimientos políticos. Tomaron partido.

Los que hoy se escandalizan por lo que vulgarmente definen como "partidismo" de la prensa, deberían analizar periodos anteriores de la historia para ver que los periódicos siempre han sido partícipes de la política y que la función de los medios como creadores de opinión ha hecho, sin lugar a dudas, avanzar a la sociedad.

Como Justino Sinova afirma en su libro La prensa en la II República Española (2006): "Decir periodismo en la Segunda República es decir política".

Muchos de los grandes hombres públicos de ese periodo fueron periodistas, articulistas, empresarios de prensa o alentadores de publicaciones. Indalecio Prieto poseía su propio diario en Bilbao; Lerroux fue informador profesional buena parte de su vida; Azaña escribió durante toda su existencia en diarios y revistas; Diego Martínez Barrios tenía una imprenta...

El periodismo era entonces una "estación de paso" casi obligada hacia la política y la simbiosis entre ambas profesiones era tal que no es incierto decir que el objetivo de buena parte de los diarios de aquella época (con excepciones, claro está) no era informar, sino convencer, alentar e incluso calumniar; alabar, enaltecer o propagar ideas y defender o denostar personas.

El régimen republicano fue perfectamente consciente de la importancia del papel de la prensa como creadora de opinión y no como mera informadora. De hecho, a pesar de los aires reformadores que el republicanismo parecía tener, la República se cuidó mucho de que no siguiera vigente la Ley de Prensa liberal y tolerante de 1883, estableciendo cotos y legislación (amparándose en la Ley de Defensa de la República) para establecer una censura férrea a los periódicos.

Aún así, pese a la censura, el posicionamiento político de los medios de comunicación lucenses en este periodo fue claro. Aunque todos intenten esquivar el cierre vistiendo sus 
principios de republicanismo para mantenerse en la calle, las publicaciones de aquellos años no se molestaban, como muchos hacen hoy, en esconder sus ideas detrás de un halo de independencia. Casi todos declaraban sin pudor, en sus cabeceras y en los editoriales de sus primeros números, sus intenciones, defendiendo a los políticos que más se acercaban a sus intereses y vilipendiaban sin problemas a los más alejados de sus ideas.

Había periódicos que surgían exclusivamente con el objetivo de contrarrestar a otros y defender a sus políticos y sus ideas en contra de sus adversarios. Casos como Luz (que surgió en Villalba) para enfrentarse a Ariete, o como el de los dos medios de Chantada ( La Voz del Agro y Juventud) que representaron a corrientes ideológicas opuestas, constituyéndose en agentes radicalmente enemistados en virtud de sus distintos ideales.

Este desenvolvimiento no es un fenómeno de la Segunda República, sólo porque se tratase de un momento político muy activo. En realidad, el apoyo de los medios a una determinada ideología es algo casi consustancial a la prensa. En Lugo, ya a principios de siglo, circularon en Villalba dos ejemplos claros de periódicos enfrentados ideológicamente, los cuales traspasaron a sus páginas ese odio político: uno era El ratón y el otro, como no, decidió llamarse El gato. Uno era de izquierdas y otro de derechas y ambos hicieron de su confrontación su razón de ser.

Entre 1931 y 1936 nadie se escandalizaba porque los periódicos tomasen partido. Vox Populi, un periódico editado en Viveiro en aquellos años, se declaraba a viva voz "antimarxista" y en sus páginas atacó sin piedad a la Organización Republicana Gallega (ORGA), de Casares Quiroga y todos cuantos principios defendiera esta.

Los medios de comunicación de aquella época llegaban, incluso, a perder la compostura e insultar abiertamente a sus oponentes. En el Heraldo de Villalba se pueden leer insultos a Unamuno, quien es calificado como el "Duce de los rojos" y que sufría de "delírium trémens". Otros periódicos defendieron decididamente a determinados personajes públicos, como fue el caso del diario Combate (de Monforte) que se erigió en portavoz de Lerroux porque este había pasado veranos en la villa lucense, tenía un hermano militar en la zona y era amigo del director.

\section{Metodología: acotación temporal, espacial y medios analizados}

El periodo estudiado ha sido el comprendido entre la proclamación de la República (14 de abril de 1931) y la fecha de aprobación del referéndum del primer Estatuto de Autonomía de Galicia (28 de junio de 1936), ya que ambas son hitos en la Historia de Galicia.

La acotación espacial es toda la provincia de Lugo y en total se pueden contabilizar 27 publicaciones: cuatro son de Lugo capital; una de O Incio; seis de Villalba; dos de Monforte; cuatro de Mondoñedo; dos de Sarria; tres de Ribadeo; una de Foz; y dos de Chantada. A ellas hay que sumar dos revistas literarias: Galiza, editada en Mondoñedo; y Yunque, en Lugo capital. 
Dado que el objetivo de la investigación es analizar la ideología de las publicaciones y contemplar cómo contribuyeron en la construcción del proceso autonómico (teniéndose en cuenta que muchos de los periódicos y revistas dejaron de publicarse antes de junio de 1936), la investigación se limita a analizar su contenido ideológico y a intentar inferir, en base a su línea editorial, su probable postura ante el plebiscito del 28 de junio de 1936.

Los medios que sí pervivieron hasta esa fecha han sido analizados detenidamente. En los que se conservan todos los ejemplares se ha estudiado el mes de junio completo para analizar cómo se trató la campaña previa a la aprobación del Estatuto; en los que no, se han analizado los ejemplares disponibles.

Conviene aclarar que muchos de los ejemplares fueron buscados hace más de quince años, cuando no existían los medios de digitalización que hoy en día existen, por lo que muchos de los párrafos incluidos en la investigación fueron tomados de puño y letra, es decir, copiados de los originales. Lamentablemente, muchos de estos no pueden ser reproducidos porque ya no se conservan.

La base de la investigación han sido los propios periódicos y publicaciones editados en la provincia de Lugo durante la II República. Para el trabajo de campo se consultaron los siguientes fondos hemerográficos, en los cuales se centró la búsqueda de publicaciones:

Tabla 1: Fondos hemerográficos consultados.

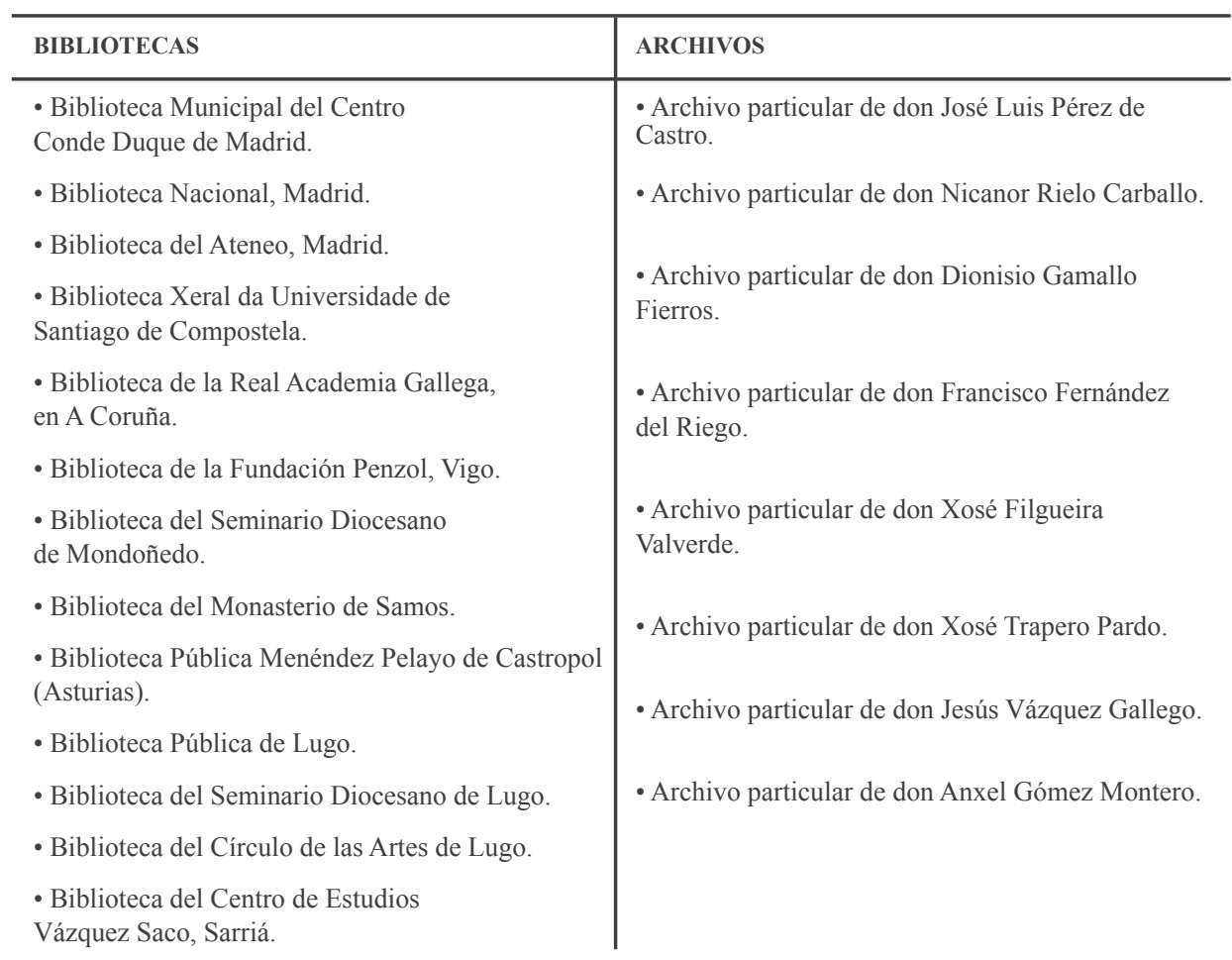


De las cuatro publicaciones que coincidieron en Lugo capital ( $\mathrm{La} \mathrm{Voz} \mathrm{de} \mathrm{la} \mathrm{Verdad,} \mathrm{El}$ Progreso, Alborada y Vanguardia Gallega), sólo una (El Progreso) pervive hoy. Los cuatro medios de la capital coincidieron en comportarse como medios de acción política y se caracterizaron, en general, por su conservadurismo, aunque con alguna excepción.

La Voz de la Verdad fue un medio al servicio de la Iglesia y, como tal, muy centrado en los postulados de la derecha; El Progreso era, entonces, un medio liberal; Alborada fue el órgano del tradicionalismo a ultranza; y Vanguardia Gallega fue el único que defendió posturas autonomistas.

Vanguardia Gallega desapareció el 26 de mayo de 1933 por motivos económicos. En él colaboraron hombres como Bóveda, Castelao, Otero Pedrayo, Paz Andrade o Suárez Picallo, es decir, prácticamente todos los que después sacaron adelante el proyecto estatutario. Eso sí, aunque colaboraron todas estas primeras figuras políticas, el diario fue obra del trabajo sin descanso de los hermanos Evaristo y Juan Antonio Correa Calderón, verdaderos artífices de la publicación.

En Villalba, en la comarca de A Terra Chá, se llegaron a editar seis publicaciones en estos años (Unión Ciudadana, Ariete, Luz, El Progreso villalbés, Heraldo de Villalba y Faro Villalbés). Unión Ciudadana fue un medio al servicio de la dictadura; Ariete forma parte de la memoria perdida de la comarca porque no se conserva ni un solo ejemplar y sólo se sabe de esta publicación por sus controversias con otros medios coetáneos; Luz fue el paladín democrático; El Progreso Villalbés ejerció de portavoz de los católicos; el Heraldo de Villalba se caracterizó por sus recelos ante el régimen republicano y el Faro Villalbés fue el contrapunto defendiendo a ultranza el régimen.

En la costa lucense, la actividad periodística también fue prolífica en esta época. En Ribadeo se editaron La Comarca, Las Riberas del Eo y Bandera Católica. En Foz, Despertar. En Viveiro se dieron cita Vox Pópuli (de ideología antimarxista) y El Momento, mucho más ecléctico en sus principios.

La Comarca fue un semanario dirigido por Francisco Álvarez Lanza, miembro del Seminario de Estudios Gallegos, quien acabó en el exilio por sus tesis autonomistas; mientras que Las Riberas del Eo siguió la línea marcada por su director, José María Puebla Pumariño, antiguo simpatizante del maurismo.

Bandera Católica estuvo promovido por las Juventudes de Acción Católica y la junta parroquial. Su contenido, como es de suponer, estuvo íntimamente vinculado a la Iglesia.

El diario de Foz, Despertar, se presentó a sus lectores como "Órgano del Comité de Salud Pública Focense" y vio la luz pocos meses antes del estallido de la Guerra Civil, concretamente el 7 de abril de 1936.

El Comité de Salud Pública intenta aparecer como una organización apolítica, pero ello no impide que convierta la política en su centro de ocupación. Así, con el tiempo, el periódico dejará de presentarse como órgano de esta asociación para adoptar en su cabecera el título de "Semanario republicano", mucho más acorde con su línea editorial. 
El periódico focense afirmaba, en su primer número, que nacía con intención de renovar la vida política de Foz. En su declaración de intenciones de ese primer día de publicación, afirmaba que quería "redimir a Foz de esclavitudes caciquiles y de la apatía que aquel pone en el ejercicio de sus deberes y derechos cívicos".

Creado por un grupo de jóvenes de la localidad, apoyados en la figura del conservador Salgado Toimil, Despertar se erige desde el primer momento en valedor absoluto de la verdad, lo que supondrá a la larga para la publicación una trayectoria muy difícil, llena de controversias y encontronazos con la censura republicana.

En la zona de Monforte de Lemos se publicaron tres periódicos: Ágora, El Combate y Siembra, este último en O Incio. El primero se lanzó el 3 de enero de 1932 y fue dirigido por Juan Mariño López. Surgió con una reconocida tendencia izquierdista, expuesta ya en el editorial que, a modo de declaración de principios, se publicó en el primer número. En cualquier caso, la publicación pretendía influir decisivamente en la vida política de Monforte y aspiraba a ser "la asamblea en la que se deciden los destinos de la localidad".

La petición de la publicación del seminario la hizo Pablo Nóvoa Somoza, un boticario de una familia influyente de Monforte formada por once hermanos y que, curiosamente, no tenía una tradición izquierdista reconocida. No obstante, el director de la publicación, cuyo nombre es imposible de saber porque no aparece en ninguna parte en el semanario, sí que debió ser un importante izquierdista.

Dos años más tarde de la aparición de Ágora, en Monforte vio la luz otra publicación, El Combate, que salió a la calle el 9 de septiembre de 1934, en pleno régimen republicano, siendo alcalde de la Ciudad del Cabe Manuel Maseda Cadórniga.

El Combate nació con un planteamiento muy diferente al de Ágora: mientras que el semanario se consideraba defensor de las ideas de izquierdas, El Combate quiere dar cabida a todas las tendencias ideológicas. En sus páginas participaron desde militantes de las JONS hasta destacados defensores de la República.

Su director en la primera época, Jesús Ramos Rodríguez, llegó a vocal de la comisión gestora del Ayuntamiento, presidida en aquel momento por Rosendo Vila Fernández, quien también publicó bastantes artículos en el diario. En suma, fue una publicación conservadora y católica, órgano de expresión de la Federación de Sindicatos Agrarios. Quien dirigía y controlaba su opinión era el abogado Antonio Maseda Bourio.

En Mondoñedo, el panorama periodístico fue el siguiente: entre 1931 y 1936 apareció y desapareció (en diferentes etapas) La Voz de Mondoñedo, una publicación que primero fue semanario, luego quincenario y que también cambió su orientación ideológica desde el liberalismo monterista de sus inicios (el que apoyaba al sector del Partido Liberal de Montero Ríos), hasta su etapa final, en la que no se opone al Estatuto de Autonomía de Galicia pero tampoco lo apoya.

Hasta 1940 se publicó también Mondoñedo, una publicación que se definía como contraria a la actuación de Avelino Montero Villegas. Junto a ambas, destaca la que fue, quizá, la 
publicación más importante de la época en Mondoñedo: Galicia Social y Agraria, que contaba (según las crónicas) con 16 páginas y 1200 subscriptores.

Galicia Social y Agraria y Vallibria (un semanario dirigido por José Trapero Pardo cuyo primer número salió a la calle el 2 de marzo de 1930) fueron, sin duda, las joyas periodísticas de la comarca en la II República.

Pese a que Vallibria contó con la colaboración de destacados galleguistas (Alvaro Cunqueiro, Juan Fernández del Riego y José Ramón Santeiro) se mostró paradójicamente contraria al Estatuto de Autonomía de Galicia. La declaración de principios del semanario (que se vendía al precio de dos pesetas) deja clara su intención de no tomar parte en la agitada vida política del momento. En su primera página del primer número y firmado por redacción se señala:

Mal juzgarán los que, por haber nacido Vallibria en una época de desatadas pasiones políticas, intenten buscarle un casillero dentro del cual defienda tendencias determinadas; por entre la turbamulta de los partidos políticos pasará Vallibria mirando siempre de frente, sin que sus flancos, por inclinarse a un lado o a otro, rocen las divisorias (02/III/1930).

La figura de Trapero Pardo es, sin duda, el eje de Vallibria. Y no sólo porque fuera el director de la publicación, sino también porque colaboró activamente en su redacción. Trapero escribía las cuatro columnas que conformaban la primera página y que se publicaban bajo los títulos fijos de "Semanal", "Pantoscopio", "Páginas históricas" y "Femenina". Cuando firmaba notas en el interior, que también lo hacía con frecuencia, firmaba bajo el seudónimo de "Tute".

En las cuatro páginas que publicaba Vallibria ocupaba un lugar muy importante el mundo agrario, el cual desde siempre tuvo una relevancia muy especial en la provincia de Lugo debido al amplio sector de población que vivía de él.

Al llegar las elecciones a las Cortes de marzo de 1931, Vallibria, con su estilo paternalista, fue explicando a los lectores (en números sucesivos) lo que a su modo de ver tenían de bueno y de malo los distintos partidos políticos que concurrían a los comicios. Sin embargo, a pesar de esta aparente ecuanimidad, el semanario apostó claramente por la Unión Monárquica. En la columna "Semanal" se apunta lo siguiente:

No voy aquí a discutir si los planes de la Unión Monárquica son o no los llamados a salvar a España, pero sí es cierto que el procedimiento por ella adoptado es acertadísimo. La Historia es la muestra de la vida y pretender gobernar a un pueblo prescindiendo de sus tradiciones es tan lógico como pretender hacer un cauce para un río desconociendo completamente su caudal e impetuosidad. Se equivocan, por lo tanto, los que, llevados por el frenesí de la innovación y prescindiendo del pasado, quieren derrumbar nuestras instituciones tradicionales sustituyéndolas por otras nuevas y advenedizas (22/03/1931).

En Sarria, la actividad periodística de la época la protagonizaron La Voz de Sarria, que sólo se publicaba los días de feria; y Loita, ambos dirigidos por Antonio Páramo Sánchez. La primera apareció el 20 de septiembre de 1931 y se publicó solamente los días 6 y 20 de cada mes. Es posible concretar la fecha exacta en la que apareció por una carta publicada en el periódico El Progreso (Lugo) el 27 de septiembre de 1931, en la que se hace referencia 
a su reciente surgimiento. Lo único que nos permite hacernos una idea de la tendencia política de la publicación es que su director, Antonio Páramo, dirigió Loita (1933), una publicación quincenal que apareció en la villa bajo el subtítulo de "Órgano del Centro Republicano de Sarria” y que fue un medio altamente favorable a la Autonomía de Galicia.

Para cerrar el círculo de publicaciones que se editaron en la provincia de Lugo durante los cinco años del estudio, hay que incluir también dos medios que se difundieron en Chantada: La Voz del Agro y Juventud. Ambos periódicos representaron a corrientes ideológicas opuestas y se constituyeron en agentes radicalmente enemistados en virtud de sus distintos ideales.

Las páginas de estos periódicos, repletas de proclamas y de ataques al medio informativo de la competencia, permiten dibujar una realidad llena de contrastes y de debate en el seno de esta villa del sur de la provincia de Lugo y en su área de influencia, que comprendía pueblos como Taboada, de cierta relevancia poblacional.

\section{Desarrollo del artículo}

\subsection{Marco referencial: un medio para cada pensamiento}

El nacionalismo gallego (nacido como tal entre 1916 y 1918 por la evolución del regionalismo previo) no había sido un actor político relevante antes de la llegada de la República. A pesar de su indudable riqueza discursiva, sus organizaciones no habían conseguido salir de la marginalidad sociopolítica. Será justamente la nueva situación creada por la República la que le permitirá desarrollarse lo suficiente para empezar a tener una presencia que, aunque menor, no puede ser catalogada de despreciable en el escenario político.

Pese a todo, el drástico cambio político que sacudió España el 14 de abril de 1931 fue inesperado para muchos. Pocos de los principales diarios gallegos eran republicanos y los nuevos partidos triunfantes en las elecciones generales de junio se encontraron con que no contaban con el apoyo que necesitaban en el campo periodístico. Y eso en una época en la que la ideologización de las publicaciones era la tónica general.

La República no dudó en ponerse manos a la obra para crear sus propios medios, o por lo menos lo intentó, pero en Galicia la mayoría de estas publicaciones (vinculadas a partidos progresistas) duraron lo mismo que las formaciones políticas que los auspiciaban, es decir, un suspiro. Muchas de las publicaciones que aparecieron durante esos convulsos años desaparecieron rápidamente, algunas sólo unos pocos meses después de surgir.

La falta de medios, la ausencia de un proyecto editorial serio y su excesiva dependencia y vinculación de los partidos políticos fueron las claves comunes en la mayor parte de la prensa gallega y lucense de la II República.

El objetivo de la prensa de esa época fue claramente convencer, alentar y defender ideales. Muchos de los medios surgidos en la provincia de Lugo durante este periodo fueron un fiel reflejo de esta circunstancia. Algunos, incluso, surgieron en núcleos de población pequeños 
con el único objetivo de plantar cara a un medio de ideología contraria. Se puede afirmar que en Lugo (como en toda España en aquel momento y casi como ocurre de nuevo hoy en día) había un medio para cada pensamiento.

Dos medios que se editaron coetáneamente en Chantada en esta época ( $L a$ Voz del Agro y Juventud) fueron un fiel reflejo de este rivalidad política buscada. Ambos se presentaron como republicanos, aunque ambos dudan desde sus páginas de la sinceridad política de la competencia. Mientras Juventud, vinculado a la derecha, sólo defendió la parte social del nuevo régimen, La Voz del Agro (que fue un diario eminentemente dedicado al medio rural) sólo intervino en política para enfrentarse a Juventud. Ambos periódicos se trataban de forma tan despectiva que Juventud se refería al periódico rival como "el arado".

En el Lugo de ese entonces, los medios de comunicación no dudaban en participar en la sociedad como armas políticas. En Sarria hubo una cabecera que se llamó Loita (Lucha, en castellano). Un periódico que sale a la calle con este nombre desde luego no tiene intención de ser un mero espectador de la realidad. Loita fue el órgano del partido republicano en Sarria.

En la II República no había ocultación de ideales ni disimulo en los medios de comunicación. A diferencia de lo que ocurre hoy en día, en aquellos años los medios lucenses exhibían orgullosos en sus cabeceras sus ideologías. Todo grupo de acción necesita un medio de expresión, que lo es también de cohesión, movilización y adoctrinamiento (Cal y Pérez, 1993) y ese axioma, en la II República, se cumplió a rajatabla.

El Faro Villabés, vinculado a la ORGA de Casares Quiroga (el único ministro gallego del régimen republicano) se presentaba como paladín de la organización republicana gallega; $E l$ Progreso Villalbés fue el portavoz de la CEDA de Gil Robles, el partido de la derecha; y Vox Pópuli, que se editó en Viveiro, se definía a sí mismo como "antimarxista" y "anti-ORGA".

Amparándose en la actitud hostil de parte de la prensa, el gobierno republicano se dotó de normas que le permitieran controlar ciertos radicalismos. A través de la Ley de Defensa de la República (20 de octubre de 1931) se podía proceder a la suspensión de publicaciones sin que mediara actuación judicial.

Al día siguiente, La Voz de Galicia publicó el texto de la Ley de Defensa y la comentó el día 23. La justificaba porque se había aprobado con carácter de excepción, con el fin de mantener el orden en los momentos iniciales de la República; y por tiempo limitado, es decir, sólo mientras durasen aquellas Cortes. En cuanto a los artículos que afectaban a la prensa, $L a$ Voz quiso dejar claro que aquella ley podía servir para poner coto a la malevolencia y a la insidia, pero subrayó que era peligroso "evitar la crítica sana, bien encaminada y justa, que al señalar defectos podría contribuir a su corrección”.

La Voz de Galicia, pese a todo, creyó en las palabras de Azaña, que en contestación a un diputado en el Congreso aseguró que esta ley no iba "contra la prensa limpia que vive a la luz del día, sino contra las pequeñas bellacadas clandestinas, los libelos, esos reptiles que viven a la sombra y van con la burla o la mala pasión desacreditando a la República" (Román Porta, 1997). 
El principal periódico gallego o tuvo suerte o supo hacerlo bien y no sufrió ni una sola suspensión en los años de la República, a pesar de no estar siempre de acuerdo con la actuación del Gobierno. Sin embargo, no todos los medios gozaron de la misma experiencia. Rastreando precisamente en las mismas páginas de La Voz de Galicia se puede encontrar un artículo de protesta ante una suspensión sufrida por el diario $A B C$ :

Hoy no se recibirá $A B C$. Hasta el domingo no volverá a aparecer el importante periódico que -ideología y distingos políticos aparte- es honra y prestigio de la prensa española. Como periodistas nos duele la medida contra él gubernativamente dictada, al igual que otras anteriores. En todo instante fuimos opuestos a la coacción oficial sobre la libre expresión de las ideas, serena, recta y noblemente proclamadas. Cuantas veces hemos sufrido sus iras, de un sector o de otro, no fue sin nuestra firma protesta. Y más han de parecernos sensibles multa y censura si se practican bajo regímenes de libertad y democracia y contra un órgano de opinión correcto y mesurado de tono y de tan considerable autoridad como $A B C$. Es un deber expresarlo al lamentar el percance del distinguido colega (30/XI/1931).

En este panorama, con unos medios de comunicación totalmente politizados, es imprescindible esbozar algunas claves de lo que fue el panorama político de Lugo durante la II República para pasar después a describir el panorama periodístico.

Se podría afirmar que los postulados del liberalismo radical, que fueron la base ideológica del régimen republicano, no se llevaron a la práctica en Lugo en lo tocante al ejercicio de la soberanía popular. Es decir, no se puede afirmar que hubiera una organización racional de los partidos políticos en la provincia de Lugo durante la Segunda República. Más bien, la realidad política de la provincia se fue fraguando a medida que se confeccionaron extravagantes alianzas a raíz de las convocatorias electorales.

La coalición de fuerzas establecidas en Lugo tras las elecciones a Cortes de 1933 se podría definir (siendo comedidos) cuando menos como peculiar. Este adjetivo se queda corto para definir lo que pasó tras los comicios de 1936. En la política lucense de aquella época prevalecieron conceptos como la indisciplina y el transfuguismo. Se puede afirmar que los personalismos siempre tuvieron más peso que la obediencia de partido o los programas.

La capital, con una mayor educación política que impidió que se llevasen a cabo excesivas manipulaciones a la hora de emitir y contabilizar los sufragios, tuvo menos irregularidades que la provincia. Sin embargo, en muchas zonas rurales no se contó con la misma suerte y no pudieron librarse del caciquismo a la hora de estructurar sus gobiernos locales.

En Lugo, en aquella época, se efectuaron nombramientos de carácter gubernativo que a la postre significaron que en las corporaciones municipales y provinciales se situara a gestores adictos a una determinada opción política y así se dieron paradojas como que en las elecciones municipales del 12 de abril de 1931 hubiera un triunfo aplastante de los monárquicos mientras que en la capital el triunfo fue para los republicanos.

Los periódicos de la época describieron la elección de 21 concejales monárquicos, entre ellos Ángel López Pérez, que había sido alcalde de la ciudad durante la dictadura de Primo de Rivera, tres republicanos y tres socialistas. Sin embargo, a pesar de la victoria de los monárquicos, la instauración de la República se celebró con gran algarabía. 
El encargado de proclamar el nuevo régimen en la provincia desde el balcón de la Casa del Ayuntamiento de Lugo fue Rafael de Vega Barrera, presidente de ALR (Alianza Republicana). Sus palabras desde la Casa Consistorial llamaron a la cordura y a la sensatez, recomendando a los lucenses a disolverse pacíficamente (Barreiro Fernández, 2007).

En cualquier caso, el resultado de estas elecciones fue anulado por el logrado en la siguiente convocatoria, el 31 de mayo de 1931. Instaurada ya la República, se produce una desbandada en el grupo de los monárquicos. Así, el resultado en Lugo capital pasó a ser de trece concejales de ALR, doce socialistas, uno de Derecha Liberal Republicana (DLR) y otro más de la ORGA.

Aunque estas fueron las últimas elecciones municipales celebradas en la capital lucense durante la II República, sus resultados no persistieron en el tiempo, puesto que se produjeron cambios. Durante el "bienio negro", fruto de la rebelión del otoño de 1934, las autoridades procedieron a eliminar políticamente a la oposición instalada en los ayuntamientos lucenses, sustituyendo a sus representantes por gestores adictos al nuevo Gobierno. Los concejales suspendidos en la capital fueron todos los socialistas, los de la ORGA, los de DLR y siete de ALR. Los nuevos ediles fueron diez del Partido Republicano Radical (PRR), con Camilo López Pardo de alcalde; y doce de la UDA, un partido vinculado a la CEDA.

La vida política municipal lucense sufrió nuevos cambios tras el triunfo del Frente Popular en las elecciones constitucionales de febrero de 1936, aunque es preciso aclarar que en Lugo el Frente Popular no era tal sino una coalición de centro-izquierda con exclusión de galleguistas y socialistas. Además, se produjeron nuevas designaciones colocando en las gestoras a concejales adictos al grupo de Izquierda Republicana (IR).

A principios de marzo de 1936 se produjo este cambio en la capital y la gestora municipal pasó a estar constituida por once concejales de la IR, entre ellos el alcalde (Francisco Lamas), ocho del PSOE, ocho de Unión Republicana (UR) y dos del Partido Galeguista (PG).

Mientras esto ocurría en Lugo, hay que destacar que la ausencia de limpieza en las elecciones fue uno de los principales problemas de las elecciones durante la II República no sólo en Lugo, sino en Galicia en general y en toda España. La existencia de caciques dentro de los partidos republicanos, la falta de tradición electoral y el hecho de que no existieran las elecciones municipales antes de 1934 (los alcaldes eran puestos en su cargo a dedo) dificultaron e impidieron esa limpieza electoral que los republicanos pretendían cuando llegaron al poder.

Es importante tener en cuenta todos estos datos a la hora de interpretar los resultados expuestos a continuación, que son las tendencias de voto en las elecciones a Cortes en Galicia:

- Comicios de 1931. Ganan las elecciones las coaliciones republicano-socialistas (el partido más votado es la ORGA), obteniendo pocos escaños la derecha. El Partido Galeguista consiguió tres escaños. En general, Galicia contaba con un 10\% de diputados en las Cortes. 
- Comicios de 1933. Triunfan los partidos de derechas, perdiendo el Partido Galeguista sus tres escaños. El Partido Radical, ya en su fase más conservadora, fue la fuerza más votada en Galicia.

- Comicios de 1936. El triunfo del Frente Popular es aplastante en Galicia, menos en Ourense, donde gana la derecha. En estos últimos comicios, los gallegos votan contra el poder, manteniendo un comportamiento semejante al de los territorios más avanzados del Estado español. En ningún momento las candidaturas de derechas lograron acercarse al número de sufragios de las de izquierdas.

Lo cierto es que, dejando al margen la más que cuestionada limpieza electoral de los procesos, todos estos resultados se dieron con unos índices de participación ciudadana elevadísimos. En la investigación titulada Participación y abstención electoral: La Segunda República en perspectiva comparada, de Carmen Ortega Villodres, se demuestra que la asistencia a las urnas durante el periodo republicano fue la más alta de la historia política española, aunque hubo fluctuaciones entre los comicios de 1933 (donde bajó la participación) y los producidos tres años después, en los que subió (tabla 2):

Tabla 2: Índice de participación de los gallegos durante los tres comicios del periodo

\begin{tabular}{lccc}
\hline & $\mathbf{1 9 3 1}$ & $\mathbf{1 9 3 3}$ & 1936 \\
\hline La Coruña & $64.58 \%$ & $56.06 \%$ & $70.06 \%$ \\
\hline Lugo & $67.97 \%$ & $68.74 \%$ & $77.2 \%$ \\
\hline Ourense & $67.69 \%$ & $70.26 \%$ & $83.9 \%$ \\
\hline Pontevedra & $52.19 \%$ & $55.52 \%$ & $58.6 \%$
\end{tabular}

Fuente: Elaboración propia 2011

Visto el incierto panorama político gallego y lucense, se entiende mejor el panorama periodístico que se dio en la provincia de Lugo durante estos años. Sin el conocimiento de ese contexto sería imposible explicar que en una provincia como Lugo, en sólo cinco años (1931-1936) vieran la luz un total de 27 publicaciones periódicas.

\subsection{Trabajo de campo. Análisis de los medios en relación a su posición autonomista}

Hubo medios gallegos (y concretamente lucenses) que supieron ver la importancia del debate autonómico y se colocaron en posiciones determinadas. Entre los que lo hicieron a favor del Estatuto podemos destacar a Loita (Sarria), a Faro Villalbés (Terra Chá) y a La Comarca, que vio la luz en Ribadeo y que mantuvo un compromiso galleguista de tal calibre que llevó a Lanza, su director, al exilio. 
En la provincia de Lugo, curiosamente, se puede afirmar que hubo más medios de comunicación partidarios de la autonomía a principios de siglo que cuando llegó el momento del referéndum de 1936. En 1930 había un semanario republicano autonomista (Ahora) que duró poco tiempo; en abril de 1932 surgió La República, que tampoco vivió lo suficiente para apoyar el Estatuto en su recta final. Aunque quedan fuera del alcance de este estudio, conviene destacar que, entre 1915 y finales de la década del veinte, se editaron varios periódicos en la región y algunos de ellos (A Xusticia) fueron más que autonomistas. De hecho, esta publicación fue el órgano de propaganda del Comité Regionalista de Villalba. Además, aparecieron revistas en dicha comarca, como Aurora o La Voz Villalbesa, que también atendieron y propagaron el hecho autonomista e, incluso, acogieron voces independentistas.

Entre los medios que se posicionaron en contra del Estatuto en la provincia de Lugo destacaron, por su especial virulencia en la oposición, La Voz de la Verdad y Alborada, ambos de Lugo capital. Es importante subrayar que ambos coincidieron en pensar que el mejor castigo para el Estatuto era la indiferencia.

Durante la II República se llegaron a producir casos tan curiosos e imposibles hoy en día como que un periódico (en este caso, La Voz de la Verdad) casi no dedicase espacio informativo al referéndum convocado para la aprobación del Estatuto y, en cambio, en una de sus secciones de opinión ("Entre col y col") hubiese constantes artículos en contra de la autonomía.

El Progreso, el cual paradójicamente es el único medio de comunicación que ha pervivido del grupo, mantuvo cierta equidistancia e independencia a la hora de abordar el tema autonomista. Aunque no se puede decir que apoyara directamente el autogobierno de Galicia, sí es razonable defender que sostuvo una postura respetuosa con el proceso autonomista.

Resulta evidente, tras la investigación, que fueron muy pocos los medios de comunicación de la provincia de Lugo que respaldaron el proceso. Sólo Loita (Sarria), Vanguardia Gallega (Lugo capital) y La Comarca (Ribadeo) defendieron el texto aprobado en 1932 y refrendado en 1936. El Combate (Monforte) y Siembra (O Incio) publicaron tímidos artículos a favor del proceso, pero no mantuvieron un apoyo incondicional. El resto de publicaciones, la gran mayoría, ignoraron la autonomía de Galicia o se opusieron a ella frontalmente (tabla 3): 
Tabla 3: Posiciones ideológicas de la prensa lucense durante el quinquenio analizado.

\begin{tabular}{|c|c|c|c|}
\hline & $\begin{array}{l}\text { MEDIOS DE } \\
\text { COMUNICACIÓN }\end{array}$ & & \\
\hline \multirow{4}{*}{$\begin{array}{l}\text { Lugo } \\
\text { Capital }\end{array}$} & El Progreso & Independiente & No afin pero respetuoso \\
\hline & La Voz de la Verdad & Católico y antiliberal & Rechazo frontal \\
\hline & Alborada & Conservador y antirrepublicano & Rechazo frontal \\
\hline & Vanguardia gallega (1931) & Liberal republicano & Apoyo al Estatuto \\
\hline \multirow{7}{*}{ Villalba } & $\begin{array}{l}\text { El Villalbés (editado } \\
\text { en Buenos Aires) }\end{array}$ & Españolista & Indiferente \\
\hline & Ariete (1931) & Conservador & Rechazo frontal \\
\hline & Luz (1931) & Republicano y socialista & Indiferente \\
\hline & $\begin{array}{l}\text { El Progreso Villalbés } \\
(1921-1934)\end{array}$ & Portavoz de los católicos & Enfrentamiento radical \\
\hline & $\begin{array}{l}\text { Heraldo de Villalba } \\
(1916-1931)\end{array}$ & Antirrepublicano & Indiferencia previa y rechazo posterior \\
\hline & $\begin{array}{l}\text { Faro Villalbés } \\
(1932-1936)\end{array}$ & $\begin{array}{l}\text { Portavoz del Partido } \\
\text { Republicano Gallego }\end{array}$ & Desapego autonomista \\
\hline & $\begin{array}{l}\text { La Unión Ciudadana } \\
\text { (1929) }\end{array}$ & $\begin{array}{l}\text { Defensor de la dictadura } \\
\text { de Primo de Rivera }\end{array}$ & Indiferencia absoluta \\
\hline O Incio & Siembra & $\begin{array}{l}\text { Regionalista pero } \\
\text { no nacionalista }\end{array}$ & Tímida defensa \\
\hline \multirow[t]{2}{*}{ Viveiro } & Vox Pópuli & $\begin{array}{l}\text { Republicanos radicales y } \\
\text { de derechas }\end{array}$ & Indiferencia absoluta \\
\hline & El Momento & $\begin{array}{l}\text { Izquierdistas cercanos } \\
\text { al socialismo }\end{array}$ & $\begin{array}{l}\text { Defensa tibia e irregular a lo largo } \\
\text { del tiempo }\end{array}$ \\
\hline \multirow{2}{*}{ Monforte } & Agora (1932) - Semanario & Izquierdistas & Ignora el proceso autonomista \\
\hline & El Combate (1934) & Partidarios de Alejandro Lerroux & Indiferencia \\
\hline \multirow{4}{*}{ 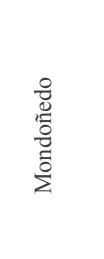 } & $\begin{array}{l}\text { La Voz de Mondoñedo } \\
\text { (comenzó como semanario } \\
\text { y luego fue quincenario) }\end{array}$ & $\begin{array}{l}\text { Liberales que apoyan } \\
\text { al sector de Montero Ríos }\end{array}$ & Indiferencia \\
\hline & Mondoñedo & $\begin{array}{l}\text { Contrarios a Avelino } \\
\text { Montero Villegas }\end{array}$ & $\begin{array}{l}\text { Indiferencia absoluta. No publica ni } \\
\text { una línea sobre el proceso }\end{array}$ \\
\hline & Galicia Social y Agraria & Conservadores y católicos & Totalmente beligerante con el Estatuto \\
\hline & Vallibria & Antirrepublicanos & Regionalistas antiseparatistas \\
\hline \multirow{2}{*}{ Sarria } & $\begin{array}{l}\text { La Voz de Sarria } \\
\text { (se publicaba sólo lo días } \\
\text { de feria: } 6 \text { y } 20 \text { de cada mes) }\end{array}$ & Republicanos & $\begin{array}{l}\text { Duró pocos meses y es imposible } \\
\text { situar su actitud }\end{array}$ \\
\hline & Loita (sólo los días de feria) & $\begin{array}{l}\text { Órgano de la ORGA (Organización } \\
\text { Gallega Republicana Autónoma) }\end{array}$ & $\begin{array}{l}\text { Claramente favorable al Estatuto } \\
\text { y a la Autonomía }\end{array}$ \\
\hline \multirow{3}{*}{ Ribadeo } & La Comarca & Galleguistas & A favor del Estatuto \\
\hline & Las Riberas del Eo & Herederos del Maurismo & Antiestaturios \\
\hline & Bandera Católica & Conservadores y católicos & $\begin{array}{l}\text { Ignora absolutamente todo lo } \\
\text { relacionado con el proceso autonomista }\end{array}$ \\
\hline \multirow{2}{*}{ Chantada } & Juventud & $\begin{array}{l}\text { Republicanos críticos ligados } \\
\text { a la derecha }\end{array}$ & Rechazo al Estatuto \\
\hline & La Voz del Agro (semanario) & $\begin{array}{l}\text { Derecha moderada fiel a la } \\
\text { República }\end{array}$ & Indiferentes al proceso estatutario \\
\hline
\end{tabular}

Fuente: Elaboración propia 2011. 
Analizado este panorama, hay una conclusión clara que se pueden extraer: durante la Segunda República, el apoyo de los medios de comunicación a un determinado partido político (o a unos determinados ideales) no condicionaba el resultado de las urnas. El denominado "cuarto poder" puede generar corrientes de opinión pero los ciudadanos siempre son libres cuando acuden a votar. Es cierto que el poder de los medios y su índice de penetración en la sociedad en aquella época no era el mismo que hoy, empero, la cobertura mediática (predominantemente indiferente hacia el Estatuto de Autonomía de Galicia) no tuvo el efecto esperado.

\section{Conclusiones}

El lenguaje autonomista ha variado muy poco a lo largo de los años. Las palabras "patria" y "separatismo" eran ya entonces patrimonio de la derecha, que veía en el Estatuto y en la autonomía el fin de un modelo de Estado y del orden establecido. Ergo, un peligro para la nación.

Del mismo modo, las corrientes nacionalistas ya esgrimían términos como "cultura", "tierra", "tradición", "bandera" o "idioma", constantes en todos los artículos de prensa publicados en defensa del Estatuto. Tampoco esto ha variado mucho hasta nuestros días.

La idea de una Galicia "subyugada" y "furgón de cola" de España sigue siendo el leitmotiv del nacionalismo, mientras que la defensa de una España "unida" y "fuerte" sigue siendo el objetivo de la derecha.

Sin embargo, hay cuestiones que han variado desde entonces. Por ejemplo, la implicación de los periódicos en el tema autonomista ha sufrido un giro radical. Hoy, cuando el Gobierno ha abierto la vía de las reformas estatutarias, ningún medio de comunicación se ha abstraído del debate. Pocos, o ninguno, dudan ya de la importancia del debate del modelo de Estado. Coherentes con esta opinión, ningún periódico ha quedado al margen de un proceso que es hoy mucho más polémico que décadas atrás.

El apoyo de los medios de comunicación al segundo proceso autonómico de Galicia, es decir, al actual Estatuto de Galicia, fue mucho más decidido que el que dieron al primer texto estatutario. Hoy en día pocos cuestionan que los medios de comunicación no funcionan a modo de espejo de la realidad: la crean, entre otras cosas, a través de "procesos de enmarcamiento" (framing) de la actualidad. En momentos de cambios en la sociedad (ya sean políticos, ideológicos o de maneras de vivir) los medios se pueden convertir (conscientemente o no) en el principal motor del cambio o, por el contrario, pueden servir de freno por causas estructurales o debido a presiones externas.

Lo cierto es que, a diferencia de lo que ocurrió con el Estatuto de 1936, durante el proceso democrático español (1975-1982) los principales periódicos de Galicia lideraron en un cierto momento los deseos de cambio y ayudaron a construir una identidad nacional gallega. En algunas cabeceras (La Voz de Galicia, El Ideal gallego) la conciencia de su papel surgió antes que en otras, pero lo cierto es que (ya fuera por la presión social, por 
el autoconvencimiento de una generación de periodistas jóvenes y comprometidos o por la propia conveniencia económica de las empresas) todos los periódicos acabaron por aceptar a Galicia como unidad diferenciada del resto del Estado Español y con derecho a su autogobierno. Esta actitud se hizo explícita durante las negociaciones del Estatuto de Autonomía, en las que la prensa gallega sirvió de altavoz de las movilizaciones populares en contra de los intentos de limitar la autonomía gallega.

Hoy, cuando el debate sobre una nueva reforma del Estatuto de Galicia está sobre la mesa, el panorama periodístico es opuesto frontalmente al de la Segunda República. Si en 1936 se puede hablar de indiferencia en muchas publicaciones y periódicos hacia el debate estatutario, actualmente tal ha sido la corriente de debate abierta que lo que se ha criticado es justamente lo contrario: el exceso de espacio dedicado por los medios de comunicación para analizar las reformas estatutarias, cuando en la calle la opinión ciudadana apenas dedicaba atención a este tema.

Se puede afirmar que estamos viviendo el proceso inverso al experimentado en Galicia durante la aprobación del primer Estatuto. Si entonces los medios fueron más que ajenos al debate estatutario (aunque el pueblo acudió masivamente a votar), actualmente los medios han insistido hasta la saciedad en el debate de las reformas estatutarias, pero el interés de los ciudadanos no lo acompaña.

En suma, no se puede decir que los periódicos gallegos hayan respaldado el fenómeno autonomista de igual forma a lo largo de la historia. Durante la Segunda República muy pocos fueron los diarios o revistas que apostaron claramente por la defensa del Estatuto de Galicia y, sobre todo y más importante, muy pocos medios entraron a fondo a debatir la cuestión autonomista.

Para explicar esta circunstancia es importante explicar una de las principales diferencias que existía entre la prensa nacionalista gallega y la del País Vasco y Cataluña. En aquella época, en Galicia, la prensa de izquierdas se aglutinaba básicamente alrededor del ideario socialista, de ahí que la prensa lucense durante la II República no fuera una prensa claramente autonomista, a diferencia de lo que ocurrió en Cataluña y el País Vasco. En Galicia no hubo una prensa autonomista de derechas como la que hubo vinculada a la Lliga Catalana, la UDC o el PNV.

En Galicia, la prensa autonomista estuvo vinculada a ideas progresistas, y, por tanto, fue una prensa minoritaria y cambiante (hay que recordar que el PSOE no siempre fue defensor de la autonomía). Durante la II República, Lugo vio nacer publicaciones de todos los colores políticos, pero si hay que subrayar una tendencia en relación a su postura ante el fenómeno autonomista, hay que subrayar que la mayoría se mostró claramente antiestatutarias. Sólo 3 de los 27 medios que se publicaron en la provincia de Lugo (entre 1931 y 1936) apoyaron decididamente el primer Estatuto de Autonomía de Galicia: Loita (Sarria), Vanguardia Gallega (Lugo capital) y La Comarca (Ribadeo).

La Voz de la Verdad, portavoz de los Sindicatos Agrarios en Lugo, transformó su postura inicial, de matiz galleguista, cuando en 1930 fue adquirido por varios propietarios particulares, todos ellos adheridos a la Confederación Española de Derechas Autónomas (CEDA), el partido de Gil Robles, que era una formación conservadora y antiestatutaria. 
Entre las publicaciones que surgieron en Lugo en aquella época (contrarias al Estatuto) destacaron, además de La Voz de la Verdad, otras como el semanario La República, que desapareció en enero de 1936; y Mundo de Ágora, otro semanario que hacían las juventudes de Unión Regional de Derechas y Agrarios.

La publicación más claramente opuesta a ese primer Estatuto de Autonomía de Galicia fue Alborada, que apareció con el subtítulo de Diario de Galicia y que fue el órgano de Renovación Española.

En resumen, la prensa lucense durante la II República fue una prensa ideologizada, mayoritariamente vinculada a la derecha, precaria en cuanto a medios y muy vinculada al mundo rural y a los políticos locales.

\section{Fuentes consultadas}

Alfonso Bozzo, A (1976). Los partidos politicos y la autonomía de Galicia 1931-1936. Madrid: Akal. Baamonde, M. A. (1994). Medio siglo de periodismo monfortino. Lugo: Diputación Provincial.

Barreiro F. y Xosé R. (2007). Historia política da Galicia contemporánea: República, guerra civil e franquismo. Arrecife: Edicións Galegas S. L.

Borrat, H. (1989). El periódico como actor político. Barcelona: Gustavo Gili.

Cal Martínez, R. y Pérez Pais, C. (1993). Repertorio bibliográfico sobre a prensa galega. Santiago de Compostela: LEA

Campos, F. (1994). A reconversión da prensa en Galicia (1892-1992). Santiago de Compostela: Servicio de Publicaciones de la Universidad de Santiago de Compostela.

Capel Martínez, R. M. (1975). El sufragio femenino durante la Segunda República española. Granada: Universidad de Granada.

Carré Aldao, E. (1917). El periodismo lucense. Monografía histórica. Lugo: Imprenta de la Moderna. Checa Godoy, A. (1989). Prensa y Partidos durante la Republica. Salamanca: Ediciones Universidad de Salamanca.

Grandío Seoane, E et álii (2006). República y republicanos en Galicia. Ateneo Republicano de Galicia.

Hermida García, M. (1987). As Revistas Literarias en Galicia na segunda república. La Coruña: Ediciones do Castro.

Luca De Tena, G. (1990). "Da empresa política á política de empresa". En Informe da comunicación en Galicia. Santiago de Compostela: Consello da Cultura Galega.

Máiz, B. (1988). Galicia na Segunda República e baixo o franquismo (1930-1976). Vigo: Edicións 
Xerais de Galicia.

Máiz, Ramón (2004). Identidade colectiva e medios de comunicación. La Coruña: Fundación Santiago Rey.

Martínez Cuadrado, M. (1969). Elecciones y partidos políticos en España (1968-1931), vol. 2. Madrid: Taurus.

Pardo de Neyra, X. (2002). Vanguardia Gallega. Ou o compromiso xornalístico lucense coa II República Española. A xeración da República na literatura, na prensa e na política galega. Lugo: Ayuntamiento de Lugo.

Pérez Pais, M. (1986). La prensa gallega durante la segunda República [microfilmada]. Madrid: ANABAD.

"Presencia de Lugo na utopía republicana. Cinco anos de ilusións e liberdade a través do espello intelectual de Galicia. 70 aniversario da proclamación da Segunda República” (2001). Lugo. Editorial Scio.

Rodríguez Castelao, D. (1974). O Estatuto de Galiza: antecedentes e comentarios. Buenos Aires: Galiza.

Román Porta, M. (1997). Historia de la Voz de Galicia 1882-1939. Vigo: Servicio de Publicaciones de la Universidad de Vigo.

Santos Galloso, E. (1990). Historia de la prensa gallega. La Coruña: Editorial O Castro.

Sepúlveda Muñoz, I. (1996). “Aproximación histórica y metodológica a la investigación del nacionalismo". En Nacionalismos e internacionalismo: una visión dialéctica, Espacio, Tiempo y Forma, 10, pp. 317 y ss. 